\title{
Effect of dietary-induced changes in plasma insulin concentrations during the early post partum period on pregnancy rate in dairy cows
}

\author{
P C Garnsworthy, A A Fouladi-Nashta, G E Mann, K D Sinclair and R Webb \\ School of Biosciences, University of Nottingham, Sutton Bonington Campus, Loughborough LE12 5RD, UK \\ Correspondence should be addressed to P C Garnsworthy; Email: phil.garnsworthy@nottingham.ac.uk \\ A A Fouladi-Nashta is now at Royal Veterinary College, Hawkshead Lane, Hatfield AL9 7TA, UK
}

\begin{abstract}
Dietary stimulation of insulin in post partum dairy cows has been found to enhance ovarian follicle development but to impair oocyte developmental competence. The objective of this study was to test the hypothesis that pregnancy rate would be improved by feeding a diet to stimulate higher insulin $(\mathrm{H})$ until cows resumed ovarian cyclic activity after parturition, and then feeding a diet to lower insulin (L) during the mating period. Each diet was fed to 30 post partum dairy cows until their first rise in milk progesterone, when 15 cows in each group were transferred to the other diet (treatments $\mathrm{HL}$ and $\mathrm{LH}$ ) and 15 cows in each group remained on their original diet (treatments HH and LL) until 120 days post partum. Treatments did not affect dry matter intake, milk yield and metabolisable energy balance. Plasma insulin concentration was elevated in cows fed on $\mathrm{H}$ compared with cows fed on L. Treatment did not affect days to first progesterone rise, first oestrus or first insemination. At 120 days post partum, $27 \%$ of cows on each of treatments $\mathrm{HH}$, LL and LH were pregnant, but $60 \%$ of cows on treatment $\mathrm{HL}$ were pregnant $(\boldsymbol{P}=\mathbf{0 . 0 2 1})$. These findings support the concept that physiological relationships between insulin and the reproductive system vary according to stage of the reproductive cycle, and suggest that pregnancy rate can be enhanced by a two-diet strategy tailored to optimise responses before and after the first post partum ovulation.
\end{abstract}

Reproduction (2009) 137 759-768

\section{Introduction}

The decline in dairy cow fertility over the past 30 years has been attributed partly to unfavourable genetic correlations between milk yield and reproductive traits, and partly to increasing imbalance of nutrients leading to metabolic stress (Pryce et al. 2004). Much emphasis has been placed on the effects of negative energy balance in early lactation on the length of the post partum anovulatory period and reduced conception rate (Beam \& Butler 1999, Butler 2003). Prolonged periods of negative energy balance are associated with suppression of pulsatile luteinising hormone secretion, reduced ovarian responsiveness to luteinising hormone stimulation and reduced oestradiol secretion by the dominant follicle, all of which can influence ovulation of the dominant follicle (Lucy et al. 1991, Butler 2003).

The most common strategy for reducing the degree of negative energy balance in early lactation is to increase dietary energy concentration by increasing the starch or fat components of the ration at the expense of forage components. Such strategies alter metabolic hormones, particularly insulin, which can influence ovarian function (Boland et al. 2001, Webb et al. 2004, Garnsworthy et al. 2008a). Gong et al. (2002a) demonstrated that feeding a high-starch diet to dairy cows for the first 50 days post partum enhanced circulating insulin concentrations and increased the proportion of cows ovulating before 50 days post partum from 55 to $90 \%$ without affecting milk yield or energy balance. Part of the mechanism could involve feedback signalling from ovarian follicles to the hypothalamus (Garnsworthy et al. 2008a) because dietary stimulation of plasma insulin in high-yielding dairy cows can increase numbers of small follicles ( $<5 \mathrm{~mm}$ diameter) and diameter of the ovulatory follicle (Garnsworthy et al. 2008b).

Although increasing insulin by dietary manipulation can be beneficial for resumption of oestrous cycles post partum, there is evidence that high insulin status might have detrimental effects on oocyte developmental competence, as indicated by rate of blastocyst production following in vitro maturation and fertilisation. For example, diets designed to increase plasma insulin concentration had negative effects on blastocyst rate in heifers (Adamiak et al. 2005, 2006) and in lactating dairy cows (Fouladi-Nashta et al. 2005). Furthermore, diets with a high fat content have beneficial effects on 
blastocyst rate in lactating dairy cows (Fouladi-Nashta et al. 2007), although they may decrease plasma insulin concentrations (Garnsworthy et al. 2008c). In addition, supplementary fatty acids can have beneficial effects on plasma progesterone concentration and uterine secretion of prostaglandin- $F_{2 \alpha}$ (Staples et al. 1998, Staples \& Thatcher 2005). There is a potential conflict, therefore, between insulin-stimulating diets, which have beneficial effects on resumption of oestrous cycles post partum, and insulin-depressing or high-fat diets, which improve oocyte quality and embryo development. This is consistent with observations in sheep and non-lactating cattle, as reviewed by Boland et al. (2001), where high levels of feeding increased follicle numbers and size of the dominant follicle but reduced early embryo development. The overall suggestion is that optimum feeding strategies might differ according to the stage of the reproductive cycle and the aim of the current study was to explore this concept.

The main objective of the study was to test the hypothesis that pregnancy rate will be enhanced by feeding a diet that stimulates higher plasma insulin $(\mathrm{H}$; Table 1$)$ until cows resume ovarian cycles and then switching to a diet that lowers plasma insulin (L; Table 1) and increases fatty acid supply during the mating period (Treatment HL). A second hypothesis was that the converse strategy (a low-insulin diet followed by a highinsulin diet; Treatment $\mathrm{LH}$ ) would reduce pregnancy rate. These strategies were compared with continuous feeding of either a high-insulin diet (Treatment $\mathrm{HH}$ ) or a lowinsulin diet (Treatment LL).

Table 1 Formulation and composition of diets designed to induce high (H) or low (L) plasma insulin.

\begin{tabular}{lll}
\hline & \multicolumn{2}{c}{ Diet } \\
\cline { 2 - 3 } & $\mathrm{H}$ & $\mathrm{L}$ \\
\hline Formulation (g/kg DM) & & \\
Grass silage & 404 & 409 \\
Maize/whole-crop wheat silage & 119 & 120 \\
Sugar beet pulp & 114 & 211 \\
Wheat & 209 & 77 \\
Soyabean meal & 76 & 85 \\
Rapeseed meal & 57 & 61 \\
Fatty acid supplement ${ }^{\mathrm{a}}$ & 11 & 27 \\
Minerals and vitamins & 10 & 10 \\
& 1000 & 1000 \\
Composition & & \\
DM (g/kg) & 556 & 553 \\
ME (MJ/kg DM) & 12.5 & 12.6 \\
CP (g/kg DM) & 179 & 181 \\
NDF (g/kg DM) & 285 & 293 \\
Starch (g/kg DM) & 182 & 98 \\
Sugars (g/kg DM) & 57 & 67 \\
Fat (g/kg DM) & 39 & 53 \\
\hline
\end{tabular}

${ }^{a}$ Megalac, calcium salts of palm fatty acids; Volac International, Royston, UK. 'bibby HiPhos: ABN Ltd, Peterborough: Calcium, 18\%; Phosphorus, 10\%; Magnesium, 5\%; Salt, 17\%; Copper, $2000 \mathrm{mg} / \mathrm{kg}$; Manganese, $5000 \mathrm{mg} / \mathrm{kg}$; Cobalt, $100 \mathrm{mg} / \mathrm{kg}$; Zinc, $6000 \mathrm{mg} / \mathrm{kg}$; lodine, $500 \mathrm{mg} / \mathrm{kg}$; Selenium, $25 \mathrm{mg} / \mathrm{kg}$; Vitamin A, $400000 \mathrm{lU} / \mathrm{kg}$; Vitamin D3 $80000 \mathrm{lU} / \mathrm{kg}$; Vitamin E, $1000 \mathrm{mg} / \mathrm{kg}$.

\section{Results}

Intake, milk production and energy balance responses

There was no treatment effect on intakes of dry matter (DM; Table 2), neutral-detergent fibre (NDF), metabolisable energy (ME) and crude protein (CP). Cows in group $\mathrm{HH}$ consumed 1.6 times as much starch $(P<0.001)$ and 0.75 times as much fat $(P<0.001)$ as cows in group LL (Table 2).

There was no treatment effect on milk yield, milk protein and milk lactose, but milk fat content was greater $(P<0.001)$ for $\mathrm{LL}$ than for $\mathrm{HH}$ (Table 2). There was no treatment effect on (mean \pm s.E.M.) live weight $(660 \pm 7.1 \mathrm{~kg})$, live-weight change from 0 to 8 weeks post partum $(6 \pm 6.7 \mathrm{~kg})$, body condition score (BCS; $2.7 \pm 0.07)$ or BCS change from 0 to 8 weeks post partum $(-0.9 \pm 0.11$ units $)$.

There was no treatment effect on net energy output in milk or ME balance (Table 2). Energy balance was negative after calving, but all groups reached positive energy balance in week 7 or 8 post partum (Fig. 1).

\section{Metabolic hormone responses}

Mean plasma insulin was higher $(P=0.039)$ throughout the experiment for $\mathrm{HH}$ than for $\mathrm{LL}$ (Table 3; Fig. 2). There was a significant $(P=0.028)$ interaction between treatment group and week of lactation; insulin concentrations increased for all groups from week 2 to 7 of lactation and was higher when cows were offered $\mathrm{H}$ than when they were offered L (Fig. 2). For groups that involved a diet change, insulin increased (LH) or decreased (HL) to levels similar to those of groups that did not involve a diet change (Fig. 2).

There was no treatment effect on mean plasma glucagon (Table 3 ), although mean plasma glucagon tended to be higher for $\mathrm{HH}$ than for $\mathrm{LL}(P=0.089)$.

There was no treatment effect on mean plasma insulin to glucagon ratio, insulin-like growth factor I (IGF1), GH or leptin (Table 3 ).

\section{Blood metabolite responses}

There was no treatment effect on plasma non-esterified fatty acids (NEFA; Table 3). Plasma glucose was lower $(P=0.015)$ for $\mathrm{LH}$ compared with $\mathrm{HH}+\mathrm{LL}$, but no other contrast was significant. Mean plasma $\beta$-hydroxybutyrate $(\mathrm{BOHB})$ was lower $(P=0.011)$ for $\mathrm{HH}$ than for $\mathrm{LL}$ (Table 3). Mean plasma urea- $N$ was lower $(P=0.004)$ for $\mathrm{LL}$ than for $\mathrm{HH}$ (Table 3).

\section{Health}

There was no difference ( $P=0.973)$ between treatment groups in mean vaginal mucus score (mean 1.08, standard error 0.15$)$, and the distribution of scores was 
Table 2 Mean feed intake and performance over the first 120 days post partum for groups of cows fed on diets that induced high (H) or low $(\mathrm{L})$ insulin before and after the first rise in progesterone post partum ${ }^{\mathrm{a}}$.

\begin{tabular}{|c|c|c|c|c|c|c|c|c|}
\hline & \multicolumn{4}{|c|}{ Treatment group } & \multirow[b]{2}{*}{ SED $^{\mathrm{c}}$} & \multicolumn{3}{|c|}{ Contrasts $^{\mathrm{b}} P$} \\
\hline & $\mathrm{HH}$ & $\mathrm{HL}$ & $\mathrm{LH}$ & LL & & $\mathrm{c} 1$ & $\mathrm{c} 2$ & c3 \\
\hline Dry matter intake $(\mathrm{kg} / \mathrm{d})$ & 22.8 & 23.6 & 22.2 & 24.2 & 0.74 & NS & NS & NS \\
\hline Starch intake $(\mathrm{kg} / \mathrm{d})$ & 4.1 & 3.1 & 3.4 & 2.6 & 0.21 & NS & NS & $<0.001$ \\
\hline Fat intake $(\mathrm{kg} / \mathrm{d})$ & 0.9 & 1.1 & 1.0 & 1.2 & 0.05 & NS & NS & $<0.001$ \\
\hline Milk yield (kg/d) & 44.6 & 44.1 & 43.7 & 44.5 & 2.49 & NS & NS & NS \\
\hline Butterfat $(\mathrm{g} / \mathrm{kg})$ & 31.0 & 35.0 & 33.7 & 36.7 & 2.03 & NS & NS & $<0.001$ \\
\hline Protein $(\mathrm{g} / \mathrm{kg})$ & 32.4 & 32.9 & 33.7 & 32.7 & 0.78 & NS & NS & NS \\
\hline Lactose (g/kg) & 45.2 & 45.4 & 44.9 & 45.1 & 0.47 & NS & NS & NS \\
\hline Milk energy output $(\mathrm{MJ} / \mathrm{d})$ & 126 & 130 & 121 & 131 & 7.9 & NS & NS & NS \\
\hline ME balance (MJ/d) & 1.7 & 2.0 & 3.0 & 1.4 & 2.49 & NS & NS & NS \\
\hline
\end{tabular}

${ }^{\mathrm{a}}$ Values for intake and milk production parameters were adjusted by covariance for previous lactation milk yield. ${ }^{\mathrm{b}}$ Orthogonal contrasts used in ANOVA were: $\mathrm{c} 1$ (HL versus HH + LH + LL); c2 (LH versus HH + LL); c3 (HH versus LL). ${ }^{\mathrm{c}}$ Standard error of the difference for comparing treatment group means.

similar among groups. Forty eight per cent of cows had a score of 0 (clear), $12 \%$ a score of 1 (flecks of pus), $22 \%$ a score of 2 (mild endometritis) and $18 \%$ a score of 3 (endometritis).

There was no difference ( $P=0.912)$ between treatment groups in the incidence of health problems requiring veterinary intervention. Veterinary treatment for retained placenta or severe uterine infection was given to five cows $(8 \%)$. Seven cows $(11 \%)$ were treated for mastitis. Four cows $(7 \%)$ were treated for lameness.

\section{Ovarian function}

Progesterone profiles indicated that $62 \%$ of cows showed only normal oestrous cycles and $38 \%$ of cows showed abnormal oestrous cycles at some point in the

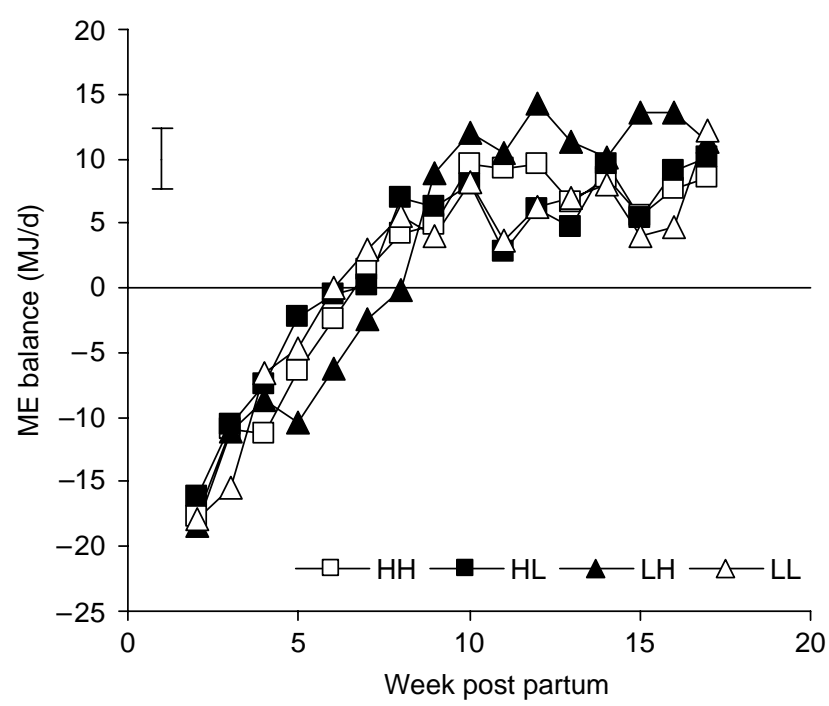

Figure 1 Metabolisable energy (ME) balance for groups of cows $(n=15)$ offered diets that induced high insulin $(\mathrm{H})$ or low insulin (L) before and after the first rise in progesterone post partum. Bar shows $2 \times \mathrm{SED}$ for comparing treatment means. Effects of treatment group, NS; group $\times$ week interaction, NS. experiment; the proportion of cows with normal oestrous cycles was not affected by treatment. Proportions of cows showing each type of abnormal cycle were: delayed ovulation type 1 (DOV1), 12\%; delayed ovulation type 2 (DOV2), 13\%; persistent corpus luteum type 1 (PCL1), 2\%; and persistent corpus luteum type 2 (PCL2), 15\%.

Cows that had not been inseminated or were not cycling normally by 60 days post partum were scanned to record the state of their ovaries (Table 4). Cows offered diet $\mathrm{H}$ at 60 days post partum had a greater $(P=0.037)$ total number of follicles and tended to have a greater $(P=0.064)$ number of small $(<5 \mathrm{~mm})$ follicles than cows offered Diet $L$ at 60 days post partum. The number of cows with a corpus luteum, as a proportion of cows scanned at 60 days post partum, was greater $(P=0.029)$ in cows offered Diet $L$ at that time than in cows offered Diet $\mathrm{H}$.

\section{Reproductive performance}

There was no effect of dietary treatment on days to first progesterone rise, days to first oestrus, days to first insemination or days to conception in cows exhibiting these events (Table 5). All the cows exhibited a progesterone rise during the experimental period and all exhibited oestrus except two cows in group $\mathrm{HH}$. Eight cows were not inseminated during the experimental period, but there was no difference among groups in their distribution.

Compared with cows in the three other groups, for cows in HL (Table 5) pregnancy rate to first insemination tended to be higher $(P=0.054)$; pregnancy rate to all inseminations was higher $(P=0.037)$; pregnancy rate as a proportion of all cows was higher $(P=0.021)$; and pregnancy rate as a proportion of cows served was higher $(P=0.015)$. Survival analysis showed that the successful pregnancy curve for treatment $\mathrm{HL}$ was significantly different from the combined curve for the 
Table 3 Mean plasma hormones and metabolites over the first 120 days post partum for groups of cows fed on diets that induced high $(\mathrm{H})$ or low $(\mathrm{L})$ insulin before and after the first rise in progesterone post partum ${ }^{\mathrm{a}}$.

\begin{tabular}{|c|c|c|c|c|c|c|c|c|}
\hline & \multicolumn{4}{|c|}{ Treatment group } & \multirow[b]{2}{*}{ SED $^{b}$} & \multicolumn{3}{|c|}{ Contrasts $^{\mathrm{a}} \mathrm{P}$} \\
\hline & $\mathrm{HH}$ & $\mathrm{HL}$ & $\mathrm{LH}$ & LL & & $\mathrm{c} 1$ & $\mathrm{c} 2$ & c3 \\
\hline Insulin (ng/ml) & 0.49 & 0.43 & 0.44 & 0.40 & 0.043 & NS & NS & 0.039 \\
\hline Glucagon (pg/ml) & 99.9 & 93.2 & 94.5 & 88.7 & 6.07 & NS & NS & NS \\
\hline Insulin to glucagon ratio (ng/ng) & 5.18 & 4.98 & 5.04 & 4.76 & 0.63 & NS & NS & NS \\
\hline $\mathrm{GH}(\mathrm{ng} / \mathrm{ml})$ & 4.92 & 3.98 & 4.10 & 4.30 & 0.677 & NS & NS & NS \\
\hline IGF1 (ng/ml) & 134 & 137 & 134 & 113 & 15.6 & NS & NS & NS \\
\hline Leptin $(\mathrm{ng} / \mathrm{ml})$ & 1.76 & 1.88 & 1.81 & 1.49 & 0.324 & NS & NS & NS \\
\hline Glucose $(\mathrm{mmol} / \mathrm{l})$ & 3.59 & 3.51 & 3.39 & 3.61 & 0.121 & NS & 0.015 & NS \\
\hline$\beta$-hydroxybutyrate $(\mathrm{mmol} / \mathrm{l})$ & 0.50 & 0.63 & 0.65 & 0.68 & 0.067 & NS & NS & 0.011 \\
\hline Non-esterified fatty acids (mmol/l) & 0.33 & 0.36 & 0.34 & 0.44 & 0.051 & NS & NS & NS \\
\hline Urea- $N(\mathrm{mmol} / \mathrm{l})$ & 2.82 & 2.51 & 2.72 & 2.33 & 0.176 & NS & NS & 0.004 \\
\hline
\end{tabular}

${ }^{\mathrm{a}}$ Orthogonal contrasts used in ANOVA were: $\mathrm{c} 1$ (HL versus $\left.\mathrm{HH}+\mathrm{LH}+\mathrm{LL}\right) ; \mathrm{c} 2$ (LH versus $\left.\mathrm{HH}+\mathrm{LL}\right)$; $\mathrm{c} 3(\mathrm{HH}$ versus $\mathrm{LL}) .{ }^{\mathrm{b}} \mathrm{Standard}$ error of the difference for comparing treatment group means.

other three treatments (Log-rank 5.01, $P=0.025$ ), indicating an increased pregnancy rate for $\mathrm{HL}$ across time as well as across groups; Fig. 3 shows that the survival curve for HL started to diverge from the other curves at 78 days post partum. Cows in group HL had significantly shorter calving intervals than those in the other three groups $(P=0.047)$.

There was no effect of vaginal mucus score, or veterinary treatment for uterine infection, on proportions of cows with abnormal cycles, days to first progesterone rise, days to insemination or days to conception (data not shown). Cows with a vaginal mucus score of 0 had a significantly higher $(P=0.01)$ pregnancy rate $(52 \%)$ than those with scores of 1 to $3(19 \%)$, but there was no effect of veterinary treatment for uterine infection on pregnancy rate.

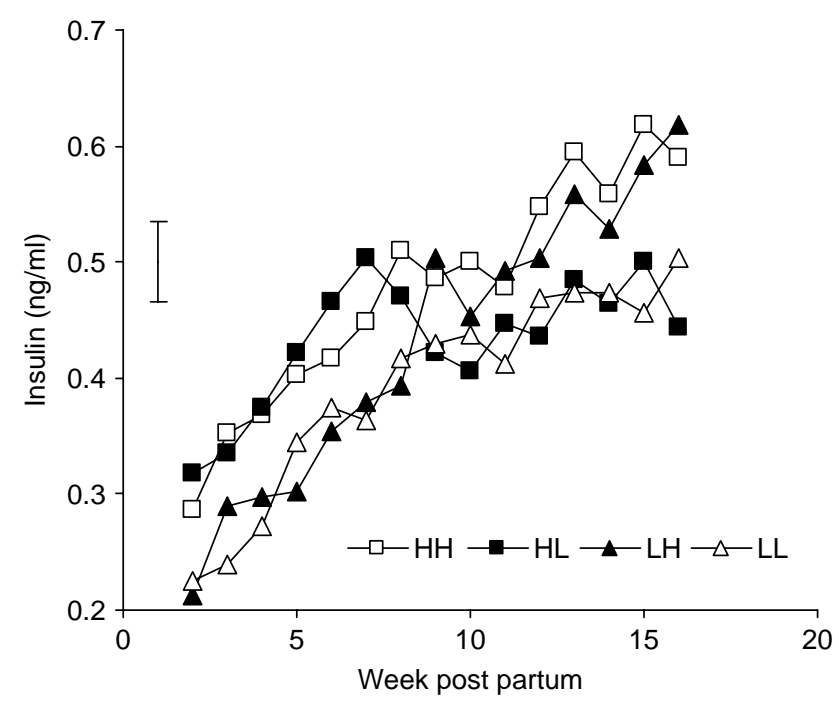

Figure 2 Plasma insulin for groups of cows $(n=15)$ offered diets designed to induce high insulin $(\mathrm{H})$ or low insulin (L) before and after the first rise in progesterone post partum. Bar shows $2 \times$ SED for comparing treatment means. Effects of group $\times$ week interaction, $P=0.028 ; \mathrm{HH}$ versus $\mathrm{LL}, P=0.039$.
Abnormal oestrous cycles affected pregnancy rate at 120 days post partum; for cows exhibiting abnormal oestrous cycles mean pregnancy rate was $13 \%$, which was lower $(P=0.003)$ than the mean rate $(49 \%)$ for cows with normal oestrous cycles. Presence or absence of a corpus luteum at day 60 did not affect pregnancy rate at 120 days post partum $(P=0.596)$.

\section{Discussion}

The main hypothesis of this experiment was that the best dietary strategy for fertility would be to feed a highinsulin diet $(\mathrm{H})$ until cows resumed ovarian cyclic activity after parturition and then to feed a low-insulin diet (L) during the mating period. The significant improvement in pregnancy rate achieved with treatment $\mathrm{HL}$ indicates that this was indeed the best strategy under the conditions of this experiment. As outlined in the introduction, feeding cows diets designed to increase plasma insulin has been found to have beneficial effects on follicular development, leading to earlier resumption of ovarian cyclic activity (Gong et al. 2002a), but can have negative effects on oocyte developmental competence (Fouladi-Nashta et al. 2005). High insulin also has adverse effects on nuclear maturation of oocytes after follicle culture (Fouladi-Nashta \& Campbell 2006). The results of this experiment support the concept that responses to nutrition can vary at different stages of the reproductive cycle.

A major aim when designing this experiment was to induce differences among treatment groups in plasma insulin, without confounding effects of differences in milk production or energy balance. Results for plasma insulin, milk production and energy balance confirm that this aim was achieved. Pregnancy responses can, therefore, be attributed to direct and indirect dietary influences on the reproductive system.

It is important to note that this experiment was performed under carefully controlled research conditions. Clearly, larger studies will be required to test 
Table 4 Follicle numbers and proportion of cows with a corpus luteum $(\mathrm{CL})$ at 60 days post partum in cows fed on diets that induced high (H) or low (L) insulin.

\begin{tabular}{|c|c|c|c|c|}
\hline & \multicolumn{2}{|c|}{ Diet at scanning } & \multirow[b]{2}{*}{$\mathrm{SED} / \mathrm{Cl}^{\mathrm{a}}$} & \multirow[b]{2}{*}{$\boldsymbol{P}$} \\
\hline & $\mathrm{H}$ & $\mathrm{L}$ & & \\
\hline Number of cows scanned & 19 & 15 & & \\
\hline \multicolumn{5}{|l|}{ Follicle numbers } \\
\hline$<5 \mathrm{~mm}$ & 6.1 & 3.1 & 1.07 & NS \\
\hline $5-10 \mathrm{~mm}$ & 4.6 & 4.3 & 0.65 & NS \\
\hline$>10 \mathrm{~mm}$ & 2.6 & 2.3 & 0.37 & NS \\
\hline All follicles & 13.3 & 9.4 & 1.24 & 0.037 \\
\hline Proportion of cows with a CL & $0.53(9 / 19)$ & $0.87(13 / 15)$ & $0.03,0.50$ & 0.029 \\
\hline
\end{tabular}

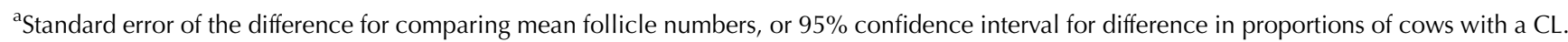

the concepts under field conditions with greater numbers of cows before they can be applied in commercial practice.

\section{Intake, production and metabolic responses to dietary treatments}

As anticipated, there was no significant difference between treatments in the intake of ME or any nutrient except starch and fat. Despite a greater butterfat content of milk from cows fed on diet $L$, there was no significant effect of diet on net energy output or energy balance. This is important when considering reproduction responses, because energy balance has been shown to affect many aspects of the reproductive system (Butler 2003, Garnsworthy et al. 2008a).

For the two treatment groups that remained on the same diets throughout the experiment, insulin was significantly higher when the high-starch diet $(\mathrm{HH})$ was fed to cows, compared with the high-fat diet (LL), in agreement with previous studies (Gong et al. 2002a, Garnsworthy et al. 2008a, 2008b). As in the study of
Gong et al. (2002a), differences in insulin between highstarch and high-fat diets were maintained throughout the experiment, with no difference in milk yield or energy balance. Insulin concentrations changed rapidly in cows that were transferred from one diet to the other, in accordance with the role of insulin in glucose homeostasis (Bauman 2000).

Plasma glucagon tended to be higher for $\mathrm{HH}$ than for $\mathrm{LL}(P=0.089)$. This is contrary to observations of Garnsworthy et al. (2008b), where glucagon decreased with increasing dietary starch concentration. In the current experiment, differences in glucagon were observed only in the first 50 days post partum, whereas the study of Garnsworthy et al. (2008b) was conducted between 60 and 70 days post partum. The differential response of glucagon to dietary starch is probably due, therefore, to interactions with insulin, which increased throughout the current study in both $\mathrm{HH}$ and $\mathrm{LL}$ treatment groups.

The lack of dietary effect on plasma GH and IGF1 is in agreement with previous studies into dietary manipulation of metabolic hormones (Garnsworthy et al. 2008b,

Table 5 Reproductive performance for groups of cows fed on diets that induced high $(\mathrm{H})$ or low $(\mathrm{L})$ insulin before and after the first rise in progesterone post partum.

\begin{tabular}{|c|c|c|c|c|c|c|c|c|}
\hline & \multicolumn{4}{|c|}{ Treatment group } & \multirow[b]{2}{*}{$\mathrm{SED} / \mathrm{Cl}^{\mathrm{b}}$} & \multicolumn{3}{|c|}{ Contrasts $^{\mathrm{a}} \boldsymbol{P}$} \\
\hline & $\mathrm{HH}$ & $\mathrm{HL}$ & $\mathrm{LH}$ & $\mathrm{LL}$ & & $\mathrm{c} 1$ & $\mathrm{c} 2$ & $\mathrm{c} 3$ \\
\hline \multicolumn{9}{|l|}{ Days post partum for } \\
\hline First progesterone rise & 32.9 & 30.3 & 26.9 & 26.4 & 5.36 & NS & NS & NS \\
\hline First oestrus & 58.2 & 53.2 & 54.1 & 51.2 & 7.04 & NS & NS & NS \\
\hline First insemination & 77.3 & 68.1 & 74.4 & 77.4 & 7.62 & NS & NS & NS \\
\hline Conception & 81.0 & 83.0 & 82.2 & 65.5 & 12.15 & NS & NS & NS \\
\hline Subsequent parturition & 413 & 404 & 418 & 423 & 8.03 & 0.047 & NS & NS \\
\hline \multicolumn{9}{|l|}{ Numbers of cows (\%) } \\
\hline Showing oestrus & $87(13 / 15)$ & $100(15 / 15)$ & $100(15 / 15)$ & $100(15 / 15)$ & $-2,10$ & NS & NS & NS \\
\hline Inseminated & $73(11 / 15)$ & $87(13 / 15)$ & $93(14 / 15)$ & $93(14 / 15)$ & $-20,20$ & NS & NS & NS \\
\hline \multicolumn{9}{|l|}{ Pregnancy rate $(\%)$} \\
\hline To first insemination & $9(1 / 11)$ & $38(5 / 13)$ & $7(1 / 14)$ & $21(3 / 14)$ & 10,68 & 0.054 & NS & NS \\
\hline To all inseminations before 120 days post partum ${ }^{c}$ & $23(4 / 17)$ & $41(9 / 22)$ & $15(4 / 27)$ & $18(4 / 22)$ & 10,50 & 0.037 & NS & NS \\
\hline At 120 days post partum (all cows) & $27(4 / 15)$ & $60(9 / 15)$ & $27(4 / 15)$ & $27(4 / 15)$ & 7,46 & 0.021 & NS & NS \\
\hline At 120 days post partum (inseminated cows) & $36(4 / 11)$ & $69(9 / 13)$ & $29(4 / 14)$ & $29(4 / 14)$ & 5,44 & 0.015 & NS & NS \\
\hline
\end{tabular}

${ }^{\mathrm{a} O r t h o g o n a l}$ contrasts used were: $\mathrm{c} 1$ ( $\mathrm{HL}$ versus $\left.\mathrm{HH}+\mathrm{LH}+\mathrm{LL}\right)$; $\mathrm{c} 2$ ( $\mathrm{LH}$ versus $\left.\mathrm{HH}+\mathrm{LL}\right)$; $\mathrm{c} 3$ (HH versus $\left.\mathrm{LL}\right)$. ${ }^{\mathrm{b}}$ Standard error of the difference for comparing treatment group means for days data, or $95 \%$ confidence interval of contrast $\mathrm{c} 1$ (benefit of treatment $\mathrm{HL}$ ) for proportions data. ${ }^{\mathrm{C}} \mathrm{Number}$ of pregnant cows divided by total number of inseminations per group. 


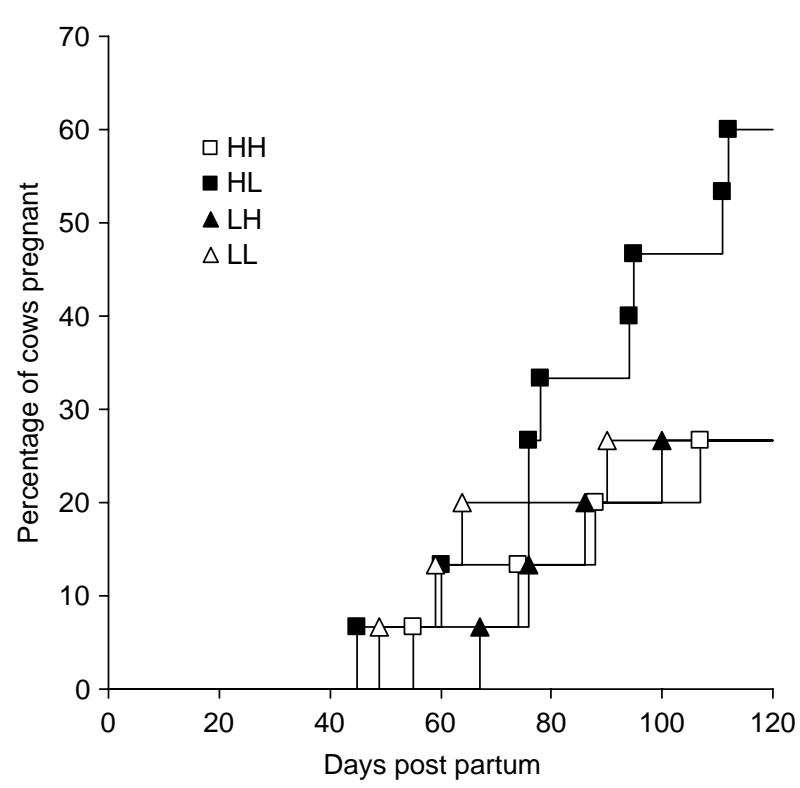

Figure 3 Number of cows pregnant between 0 and 120 days post partum (as a percentage of total cows) for groups of cows $(n=15)$ offered diets that induced high insulin $(\mathrm{H})$ or low insulin $(\mathrm{L})$ before and after the first rise in progesterone post partum. The survival curve for $\mathrm{HL}$ was higher $(P=0.025)$ than curves for the three other treatment groups.

$2008 c, 2008 d$ ) and implies that these hormones are related more to animal factors, such as milk yield, live weight and energy balance, than to diet composition (Lucy 2000). Similarly, leptin is related mainly to animal factors, particularly body fatness, with insulin being involved in regulating leptin responses to nutrition (Armstrong et al. 2003).

Of the blood metabolites measured, only glucose, $\mathrm{BOHB}$ and urea- $\mathrm{N}$ were influenced by dietary treatment. Glucose was lower for $\mathrm{LH}$ than for $\mathrm{HH}+\mathrm{LL}$, but we have no explanation for this observation because this contrast was far from significance for all measures of intake, milk production, metabolic hormones and other metabolites. Elevated BOHB is associated with NEB (Butler 2003), but there was no effect of diet on energy balance or mobilisation of body fat in this experiment. Differences in BOHB might be due to dietary sugar content, which was however higher for Diet L; sugars encourage production of butyrate in the rumen, which is converted to $\mathrm{BOHB}$ in the rumen wall. Plasma urea- $N$ is normally decreased by higher dietary starch concentrations because fermentable starch tends to decrease rumen ammonia concentrations, but the opposite effect was seen here. This might be due to increased gluconeogenesis from amino acids, induced by higher concentrations of glucagon (Garnsworthy et al. 2008d).

\section{Reproduction responses}

In the study of Gong et al. (2002a), a diet that induced higher plasma insulin concentrations in dairy cows increased the proportion of cows that ovulated by
50 days post partum (90 vs 55\%). Ovulation was not determined by ultrasound scanning in the current experiment, but $87 \%$ of cows fed Diet $\mathrm{H}$ before first progesterone rise and $97 \%$ of cows fed Diet $L$ showed a rise in progesterone before 50 days post partum, which is considerably greater than the proportions observed by Gong et al. (2002a). The most likely explanation for this discrepancy is differences in insulin concentrations between studies. For high- and low-insulin diets respectively, mean insulin concentrations over the first 50 days post partum were 0.32 and $0.21 \mathrm{ng} / \mathrm{ml}$ in the study of Gong et al. (2002a), and 0.40 and $0.32 \mathrm{ng} / \mathrm{ml}$ in the current experiment. This suggests that there is a minimum insulin concentration (between 0.21 and $0.32 \mathrm{ng} / \mathrm{ml}$ ) necessary for restoration of normal ovarian cycles post partum, which was exceeded for most cows in the current experiment. Gong et al. (2002a) noted that all cows exhibited fluctuations in $\mathrm{FSH}$ from $3-5$ days post partum and follicular waves from 7-10 days post partum, and suggested that ovulation might be limited in lowinsulin cows by functional competence of the dominant follicle or inadequate luteinising hormone secretion.

Cows were not subjected to exogenous hormonal intervention to synchronise ovulation in this study. Therefore, cows scanned at 60 days post partum would have been at different stages of the oestrous cycle. Nevertheless, the greater numbers of follicles observed for cows fed on Diet $\mathrm{H}$ at 60 days post partum are consistent with findings from other experiments, where high-insulin diets were found to increase follicle numbers in synchronised animals (Gutierrez et al. 1997a, Gong et al. 2002b, Garnsworthy et al. 2008b). Greater numbers of small follicles are associated with lower FSH concentrations, independently of circulating oestradiol, inhibin or IGF1 concentrations (Burns et al. 2005). It has been demonstrated that declining FSH and increasing luteinising hormone are associated with the differentiation and maturation of dominant follicles (Webb et al. 2004, 2007), thereby increasing the chance of ovulation in response to a luteinising hormone surge (Beam \& Butler 1998, 1999). Differentiation and maturation of dominant follicles are controlled by local ovarian growth factors that affect their response to luteinising hormone (see Webb et al. 2007). An insulin-stimulated increase in follicle numbers could increase the strength of local signals, thereby leading to better functional competence of dominant follicles. Although, in the current study, there was no apparent difference in timing of the first ovulation post partum, the difference in pregnancy rate between $\mathrm{HL}$ and LL suggests that exposure of follicles to high insulin during early development might be beneficial.

The ovulatory follicle develops over a period of $\sim 3$ months, but the final processes of selection, dominance and ovulation occur over a period of 20-40 days (Webb et al. 2004). Differences in oocyte developmental competence have been detected after dietary treatment 
periods of only 14 days in lactating dairy cows (Fouladi-Nashta et al. 2005, 2007) and 25 days in heifers (Adamiak et al. 2005). Therefore, this supports the concept that both long-term and short-term nutritional milieux might influence both follicle growth and oocyte quality.

As mentioned previously, although diets designed to stimulate plasma insulin secretion can be beneficial for resumption of oestrous cycles post partum, they can also have negative effects on blastocyst rate (Adamiak et al. 2005, Fouladi-Nashta et al. 2005). This suggests that responses to nutritionally-induced differences in plasma insulin vary at different stages of the reproductive cycle, and at different stages of follicle development, which could explain the dietary effects on pregnancy rate observed in the current study. Evidence from heifers indicates that higher concentrations of circulating insulin and IGF1 stimulate follicular growth and reduce oocyte developmental competence through direct actions on the local binding proteins and receptors of the ovarian IGF system (Lucy 2000, Armstrong et al. 2001). However, additional factors that might have contributed to the enhanced pregnancy rate for HL in the current study include the beneficial effects of dietary fatty acids on oocyte developmental competence (Fouladi-Nashta et al. 2007) and progesterone secretion (Staples \& Thatcher 2005, Garnsworthy et al. 2008b). Boland et al. (2001) reviewed nutritional effects on reproductive function across species and found consistent evidence that high dietary intake is beneficial for follicle development but reduces developmental capacity of embryos.

\section{Health and reproduction}

The overall incidence of abnormal progesterone profiles $(38 \%)$ is similar to the incidence $(44 \%)$ observed by Royal et al. (2000) in a database of 714 cows. The reduction in pregnancy rate for cows exhibiting abnormal cycles (13 vs $49 \%$ ) emphasises the need to encourage normal cyclicity.

Based on vaginal mucus score, the incidence of endometritis (40\%) was slightly higher than the incidence of $31 \%$ reported by Williams et al. (2005), although the number requiring veterinary intervention $(8 \%)$ was considerably lower. The reduction in pregnancy rate for cows with vaginal mucus scores of 1-3 compared with score 0 ( 19 vs $52 \%$ ) emphasises the need to reduce the incidence of uterine infections in dairy cows.

\section{Conclusions}

The results of this study support the original hypothesis that pregnancy rate will be enhanced by feeding a diet that stimulates higher plasma insulin until cows resume ovarian cycles and then switching to a diet that lowers plasma insulin and increases fatty acid supply during the mating period. The theory is that feeding a high-insulin diet post partum will benefit follicular development, and then feeding a low-insulin and high-fat diet during the mating period will benefit oocyte developmental competence and possibly improve progesterone status. Based on previous studies, it was anticipated that the high-insulin inducing diet would lead to a greater proportion of cows exhibiting oestrus by 50 days post partum. This was not observed, however, which indicates that there are likely to be benefits from stimulating follicular development even when time of ovulation is not altered. Previous studies further suggested that feeding a low-insulin inducing diet during the mating period would improve developmental competence of oocytes, which was supported by the improved pregnancy rates observed in cows fed on this diet.

Results of this study support the concept that responses to nutritional manipulation of metabolic hormones vary with stage of the reproductive cycle. This significant finding could partly explain why previous attempts to manipulate metabolic hormones through continuous treatment regimes have had limited success at improving pregnancy rates. The results suggest that by applying this novel concept to design a dietary strategy that induces high insulin followed by low insulin, fertility levels can be enhanced without compromising milk production in high-yielding dairy cows. Further research is required to elucidate the exact mechanisms involved, and to confirm the pregnancy rate effect with large numbers of cows under field conditions.

\section{Materials and Methods}

\section{Treatments}

Two diets were formulated to have equal concentrations of $\mathrm{DM}, \mathrm{ME}$ and $\mathrm{CP}$, but to differ in starch, fat and NDF concentrations (Table 1). Diet $\mathrm{H}$ was expected to induce relatively high plasma insulin concentrations because of its higher starch and lower fat contents; Diet $L$ was expected to induce relatively low insulin concentrations because of its lower starch and higher fat contents. These diets were equivalent to the high and low insulin diets used by both Gong et al. (2002a) and Fouladi-Nashta et al. (2005).

Sixty high-yielding multiparous Holstein dairy cows were blocked according to calving date and parity, and were allocated at random to four treatment groups. There was no difference between groups (mean \pm s.E.M.) in parity $(2.6 \pm 1.33)$ or BCS at calving (3.4 \pm 0.04$)$. Cows in group HL were fed on Diet $\mathrm{H}$ from calving until the first rise in milk progesterone and were then fed on Diet $L$ until 120 days post partum. Cows in group LH were fed on Diet $L$ and then Diet H. Cows in group $\mathrm{HH}$ were fed on Diet $\mathrm{H}$ until 120 days post partum, and cows in group LL were fed on Diet L until 120 days post partum. Milk progesterone was measured twice in a week 
(either Monday and Thursday or Tuesday and Friday mornings) and a rise in progesterone was defined as above $3 \mathrm{ng} / \mathrm{ml}$ for two consecutive samples.

\section{Feeding and milking}

Cows were housed as one group throughout the experiment, and were fed individually via electronic feeders (Roughage Intake Control feeders, Fullwood Ltd, Ellesmere, UK) that recorded feed intake automatically. Cows were milked by an automatic (robotic) milking system (AMS; Merlin, Fullwood Ltd.), which they entered voluntarily and were milked on average $2.65 \pm 0.09$ times per day. In order to encourage cows to use the AMS, $4 \mathrm{~kg}$ fresh weight of each cow's daily concentrate allocation was dispensed automatically in the AMS during milking.

\section{Reproductive management}

Cows were artificially inseminated the first or second oestrus following dietary change (or first progesterone rise for $\mathrm{HH}$ and LL), provided they had been on their appropriate diet for at least 20 days. Insemination was repeated at any subsequent oestrus until the end of the experiment at 120 days post partum. Oestrus was detected using a combination of behavioural observations, pedometer activity monitoring and milk progesterone profiles. Milk progesterone was monitored daily from 4 days before expected oestrus until signs of oestrus were detected; monitoring then returned to twice in a week until 4 days before the next expected oestrus (21 days later). Progesterone profiles were used subsequently to classify oestrous cycles as normal or abnormal (DOV1, DOV2, PCL1 or PCL2), following the definitions of Lamming \& Darwash (1998).

Uterine involution (uterine horns and cervix $<40 \mathrm{~mm}$ in diameter) was confirmed for every cow by trans-rectal ultrasound scan at 20 days post partum using an Aloka SSD500 scanner equipped with a $5-\mathrm{MHz}$ linear array transducer (Aloka Co., Ltd., Tokyo, Japan). Also at 20 days post partum, samples of vaginal mucus were collected into $50 \mathrm{ml}$ clear plastic vials to assess endometritis, following the method of Williams et al. (2005). Mucus was assessed for colour, proportion and volume of pus, and a character score was assigned as follows: (0) clear or translucent mucus; (1) mucus containing flecks of white or off-white pus; $(2)<50 \mathrm{ml}$ exudate containing $\leq 50 \%$ white or off-white mucopurulent material; and (3) $>50 \mathrm{ml}$ exudate containing purulent material, usually white or yellow, but occasionally sanguineous.

Cows that had not been inseminated, or were not cycling normally, by 60 days post partum were scanned by trans-rectal ultrasound to record numbers of ovarian follicles and corpora lutea. Pregnancy was confirmed by a veterinary surgeon at a routine monthly visit using rectal palpation between 40 and 72 days post-insemination.

\section{Recording, sampling and analysis}

Milk yield, feed intake and pedometer activity were recorded daily throughout the experiment. Live weight and BCS $(1=$ thin to $5=$ fat) were recorded weekly. Milk samples were taken twice in a week (Monday and Thursday mornings) and analyzed for fat, protein and lactose contents by infrared analysis at the National Milk Records Laboratory, Harrogate, UK, using AOAC reference method No. 972.16 (AOAC 1990), and for progesterone by ELISA (Ridgeway Scientific, Alvington, UK). The reliable reading range of the ELISA was from 1.5 to $10.5 \mathrm{ng} / \mathrm{ml}$. Samples reading $<1.5 \mathrm{ng} / \mathrm{ml}$ were taken as $1.5 \mathrm{ng} / \mathrm{ml}$; samples reading $>10.5 \mathrm{ng} / \mathrm{ml}$ were diluted to bring the reading within range. If the coefficient of variation (CV) of duplicate sample readings was $>15 \%$, the analysis was repeated. The intra- and inter-assay coefficients of variation were $<15$ and $6.6 \%$ respectively.

Feed samples were taken weekly and pooled on a monthly basis for analysis of DM, CP, NDF, starch, sugars, fat and ME, as detailed in Garnsworthy et al. (2008b).

Blood samples were taken every Wednesday at $0930 \mathrm{~h}$ for measurement of hormones and metabolites. Blood samples were analyzed for the following hormones (in each case, the reference is followed by mean assay sensitivity, intra-assay CV and inter-assay CV): insulin (Adamiak et al. 2005; $0.045 \mathrm{ng} / \mathrm{ml}$, $4.0 \%, 8.4 \%$ ), GH (Gong et al. 1997; $1.2 \mathrm{ng} / \mathrm{ml}, 3.9 \%, 11.3 \%$ ), IGF1 (Gutierrez et al. 1997b; 0.11 ng/ml, 3.8\%, 12\%), glucagon (kit supplied by Linco Research Inc., St Charles, MO, USA; $40.5 \mathrm{pg} / \mathrm{ml}, 5.3 \%$ 6.2\%) and leptin (Adamiak et al. 2005; 0.2 $\mathrm{ng} / \mathrm{ml}, 3.9 \%, 12.2 \%)$.

Blood samples were analyzed for the following metabolites on a Bayer opera autoanalyzer (Bayer UK Ltd): urea-N (Bayer kit T01 182356), glucose (Bayer kit T01 183356), BOHB (Randox kit Ranbut RB 1008) and NEFA (Waiko kit NEFA-C); intra- and inter-assay coefficients of variation were $<5 \%$.

All instances of ill health and veterinary treatments were recorded. The ultimate fate of each cow (subsequent calving or culling) was recorded to allow calculation of calving interval. For cows that were pregnant when culled, subsequent calving date was estimated as date of successful insemination plus 282 days; cows that were not pregnant when culled were omitted from statistical analysis of calving interval.

\section{Statistical analysis}

All data were analyzed using Genstat 10th Edition (Lawes Agricultural Trust, Rothamsted, UK). Orthogonal contrasts (Morris 1999) were used to test specific hypotheses. The main hypothesis of the study (that pregnancy rate will be enhanced by treatment $\mathrm{HL}$ compared with the other dietary strategies) was tested by contrast $\mathrm{c} 1$, which compared treatment $\mathrm{HL}$ with the three other treatments ( $\mathrm{HL}$ versus $\mathrm{HH}+\mathrm{LH}+\mathrm{LL}$ ). The second hypothesis (that pregnancy rate will be reduced by treatment $\mathrm{LH}$ ) was tested by contrast c2, which compared treatment $\mathrm{LH}$ with the two continuous treatments $(\mathrm{LH}$ versus $\mathrm{HH}+\mathrm{LL}$ ). Finally, contrast c3 compared the two continuous treatments ( $\mathrm{HH}$ versus $\mathrm{LL}$ ). Results are presented as treatment group means (with SED) and probability values for each contrast.

Intake, milk production, hormone and metabolite responses were examined by ANOVA. Data from the first week post partum were excluded from the analysis because of variations in the time taken for individual cows to recover from calving 
and adapt to the automatic feeding and milking facilities. Week of lactation (2-17) was included in each model, and data were blocked by cow to allow for repeated measures (i.e. the error term for comparing treatment effects was cow nested within diet). For intake and milk production data, previous lactation yield was used as a covariate to allow for any genetic difference among cows. Data consisting of days (e.g. days to first oestrus), which were not normally distributed, were analyzed by generalised linear models with a Poisson error distribution and a log link function. Data consisting of proportions (e.g. pregnancy rate) were analyzed by generalised linear models with a binomial error distribution and a logit link function.

To examine effects of treatments on time from calving to pregnancy, survival analysis was performed. Cows not pregnant at the end of the experiment were censored at 120 days post partum and Kaplan-Meier estimates of the survivor function were compared for each orthogonal contrast using a Log-rank test.

Data for type of ovarian cycle and incidence of health disorders, both of which consisted of counts, were analyzed by Fisher's Exact Test. Vaginal mucus scores were analyzed by ordinal regression using score as a single response factor, treatment group as the model term and a logit link function. Effects of mucus scores and health disorders on reproduction data were examined by generalised linear models with a Poisson error distribution and a log link function for days, and with a binomial error distribution and logit link function for proportions.

Ultrasound scanning data, obtained at 60 days post partum, were analyzed by generalised linear models with a Poisson error distribution and log link function for follicle counts, and a binomial error distribution and logit link function for proportions of cows exhibiting a corpus luteum. Because some cows on treatments $\mathrm{HL}$ and $\mathrm{LH}$ had not yet changed diets at 60 days post partum, only the diets ( $\mathrm{H}$ or $\mathrm{L})$ fed at the time of scanning were compared (cows scanned at 60 days post partum had been fed on their respective diets for at least 10 days; mean 33 days, standard error 2.9 days).

\section{Declaration of interest}

The authors declare that there is no conflict of interest that could be perceived as prejudicing the impartiality of the research reported.

\section{Funding}

This study was part of Project LK0646 in the LINK Sustainable Livestock Production programme, which was funded by SEERAD, ABNA Ltd, BOCM PAULS Ltd and Provimi Ltd.

\section{Acknowledgements}

The following people served on the Programme Management Committee of LINK Project LK0646 and made valuable contributions to the design and interpretation of the experiment: J Newbold, M Marsden, S Richards, A Boydell, W Morris, A Flint, D Garwes and D Leaver. We would like to thank the following people for technical assistance: N Saunders,
H Russell, J Gong, G Baxter, M Mitchell, N Armstrong, D Scholey, M Hunter, D Whitaker and C Smith. Statistical advice was provided by J Craigon.

\section{References}

Adamiak SJ, Mackie K, Watt RG, Webb R \& Sinclair KD 2005 Impact of nutrition on oocyte quality: cumulative effects of body composition and diet leading to hyperinsulinemia in cattle. Biology of Reproduction $\mathbf{7 3}$ 918-926.

Adamiak SJ, Powell K, Rooke JA, Webb R \& Sinclair KD 2006 Body composition, dietary carbohydrates and fatty acids determine postfertilisation development of bovine oocytes in vitro. Reproduction 131 247-258.

AOAC 1990 Official Methods of Analysis, 15 edn. Arlington, VA: Association of Official Analytical Chemists.

Armstrong DG, McEvoy TG, Baxter G, Robinson JJ, Hogg CO, Woad K, Webb R \& Sinclair KD 2001 The effect of dietary energy and protein on bovine follicular dynamics and embryo production in vitro; associations with the ovarian insulin-like growth factor system. Biology of Reproduction 64 1624-1632.

Armstrong DG, Gong JG \& Webb R 2003 Interactions between nutrition and ovarian activity in cattle: physiological, cellular and molecular mechanisms. Reproduction 61 1-12.

Bauman DE 2000 Regulation of nutrient partitioning during lactation: homeostasis and homoeorhesis revisited. In Ruminant Physiology: Digestion, Metabolism, Growth and Reproduction, pp 311-328. Ed. PB Cronje. Wallingford: CABI Publishing.

Beam SW \& Butler WR 1998 Energy balance, metabolic hormones, and early postpartum follicular development in dairy cows fed prilled lipid. Journal of Dairy Science 81 121-131.

Beam SW \& Butler WR 1999 Effects of energy balance on follicular development and first ovulation in postpartum dairy cows. Journal of Reproduction and Fertility 54 411-424.

Boland MP, Lonergan P \& O'Callaghan D 2001 Effect of nutrition on endocrine parameters, ovarian physiology, and oocyte and embryo development. Theriogenology 55 1323-1340.

Burns DS, Jimenez-Krassel F, Ireland JLH, Knight PG \& Ireland JJ 2005 Numbers of antral follicles during follicular waves in cattle: evidence for high variation among animals, very high repeatability in individuals, and an inverse association with serum follicle-stimulating hormone concentrations. Biology of Reproduction 73 54-62.

Butler WR 2003 Energy balance relationships with follicular development, ovulation and fertility in postpartum dairy cows. Livestock Production Science 83 211-218.

Fouladi-Nashta AA \& Campbell KHS 2006 Dissociation of oocyte nuclear and cytoplasmic maturation by the addition of insulin in cultured bovine antral follicles. Reproduction 131 449-460.

Fouladi-Nashta AA, Gutierrez CG, Garnsworthy PC \& Webb R 2005 Effects of dietary carbohydrate source on oocyte/embryo quality and development in high-yielding, lactating dairy cattle. Biology of Reproduction 2005 135-136.

Fouladi-Nashta AA, Gutierrez CG, Gong JG, Garnsworthy PC \& Webb R 2007 Impact of dietary fatty acids on oocyte quality and development in lactating dairy cows. Biology of Reproduction 77 9-17.

Garnsworthy PC, Sinclair KD \& Webb R 2008a Integration of physiological mechanisms that influence fertility in dairy cows. Animal 2 1144-1152.

Garnsworthy PC, Lock A, Mann GE, Sinclair KD \& Webb R $2008 b$ Nutrition, metabolism and fertility in dairy cows: 1. Dietary energy source and ovarian function. Journal of Dairy Science 91 3814-3823.

Garnsworthy PC, Lock A, Mann GE, Sinclair KD \& Webb R 2008c Nutrition, metabolism and fertility in dairy cows: 2. Dietary fat content and ovarian function. Journal of Dairy Science 91 3824-3833.

Garnsworthy PC, Gong JG, Armstrong DG, Newbold JR, Marsden M, Richards SE, Mann GE, Sinclair KD \& Webb R 2008d Nutrition, metabolism and fertility in dairy cows: 3 . Amino acids and ovarian function. Journal of Dairy Science 91 4190-4197. 
Gong JG, Baxter G, Bramley TA \& Webb R 1997 Enhancement of ovarian follicular development in heifers by treatment with recombinant bovine somatotropin: a dose-response study. Journal of Reproduction and Fertility 110 91-97.

Gong JG, Lee WJ, Garnsworthy PC \& Webb R 2002a Effect of dietaryinduced increases in circulating insulin concentrations during the early postpartum period on reproductive function in dairy cows. Reproduction 123 419-427.

Gong JG, Armstrong DG, Baxter G, Hogg CO, Garnsworthy PC \& Webb R $2002 b$ The effect of increased dietary intake on superovulatory response to FSH in heifers. Theriogenology 57 1591-1602.

Gutierrez CG, Oldham J, Bramley TA, Gong JG, Campbell BK \& Webb R 1997a The recruitment of ovarian follicles is enhanced by increased dietary intake in heifers. Journal of Animal Science 75 1876-1884.

Gutierrez CG, Campbell BK, Armstrong DG \& Webb R 1997 b Insulin-like growth factor-I (IGF-I) production by bovine granulosa cells in vitro and peripheral IGF-I measurement in cattle serum: an evaluation of IGFbinding protein extraction protocols. Journal of Endocrinology 153 231-240.

Lamming GE \& Darwash AO 1998 The use of milk progesterone profiles to characterize components of subfertility in milked dairy cows. Animal Reproduction Science 52 175-190.

Lucy MC 2000 Regulation of ovarian follicular growth by somatotropins and insulin-like growth factors in cattle. Journal of Dairy Science $\mathbf{8 3}$ 1635-1647.

Lucy MC, Staples CR, Michel FM \& Thatcher WW 1991 Energy balance and size and number of ovarian follicles detected by ultrasonography in early postpartum dairy cows. Journal of Dairy Science 74 473-482.

Morris TR 1999 Experimental Design and Analysis in Animal Sciences, Wallingford: CABI Publishing.
Pryce JE, Royal MD, Garnsworthy PC \& Mao IL 2004 Fertility in the high producing dairy cow. Livestock Production Science 86 125-135.

Royal MD, Darwash AO, Flint APF, Webb R, Woolliams JA \& Lamming GE 2000 Declining fertility in dairy cattle: changes in traditional and endocrine parameters of fertility. Animal Science 70 487-501.

Staples CR \& Thatcher WW 2005 Effects of fatty acids on reproduction of dairy cows. In Recent Advances in Animal Nutrition - 2005, pp 229-256. Eds PC Garnsworthy \& J Wiseman. Nottingham: Nottingham University Press.

Staples CR, Burke JM \& Thatcher WW 1998 Influence of supplemental fats on reproductive tissues and performance of lactating cows. Journal of Dairy Science 81 856-871.

Webb R, Garnsworthy PC, Gong JG \& Armstrong DG 2004 Control of follicular growth: local interactions and nutritional influences. Journal of Animal Science 82 E63-E74.

Webb R, Garnsworthy PC, Campbell BK \& Hunter MG 2007 Intra-ovarian regulation of follicular development and oocyte competence in farm animals. Theriogenology 68 S22-S29.

Williams EJ, Fischer DP, Pfeiffer DU, England GCW, Noakes DE, Dobson H \& Sheldon IM 2005 Clinical evaluation of postpartum vaginal mucus reflects uterine bacterial infection and the immune response in cattle. Theriogenology 63 102-117.

Received 21 November 2008

First decision 8 December 2008

Revised manuscript received 19 December 2008

Accepted 7 January 2009 